\title{
Abacavir and warfarin modulate allosterically kinetics of NO dissociation from ferrous nitrosylated human serum heme-albumin
}

\author{
Paolo Ascenzi ${ }^{\mathrm{a}, \mathrm{b}, *}$, Francesco Imperi $^{\mathrm{a}, \mathrm{b}}$, Massimo Coletta $^{\mathrm{c}}$, Mauro Fasano ${ }^{\mathrm{d}}$ \\ a Department of Biology and Interdepartmental Laboratory for Electron Microscopy, University 'Roma Tre', \\ Viale Guglielmo Marconi 446, I-00146 Roma, Italy \\ ${ }^{\mathrm{b}}$ National Institute for Infectious Diseases I.R.C.C.S. 'Lazzaro Spallanzani', Via Portuense 292, I-00149 Roma, Italy \\ ${ }^{\mathrm{c}}$ Department of Experimental Medicine and Biochemical Sciences, University of Roma 'Tor Vergata', Via Montpellier 1, I-00133 Roma, Italy \\ ${ }^{\mathrm{d}}$ Department of Structural and Functional Biology, and Center of Neuroscience, University of Insubria, \\ Via Alberto da Giussano 12, I-21052 Busto Arsizio (VA), Italy
}

Received 13 February 2008

Available online 26 February 2008

\begin{abstract}
Human serum albumin (HSA) participates to heme scavenging, in turn HSA-heme binds gaseous diatomic ligands at the heme-Featom. Here, the effect of abacavir and warfarin on denitrosylation kinetics of HSA-heme-Fe(II)-NO (i.e., $k_{\text {off }}$ ) is reported. In the absence of drugs, the value of $k_{\text {off }}$ is $(1.3 \pm 0.2) \times 10^{-4} \mathrm{~s}^{-1}$. Abacavir and warfarin facilitate NO dissociation from HSA-heme-Fe(II)-NO, the $k_{\text {off }}$ value increases to $(8.6 \pm 0.9) \times 10^{-4} \mathrm{~s}^{-1}$. From the dependence of $k_{\text {off }}$ on the drug concentration, values of the dissociation equilibrium constant for the abacavir and warfarin binding to HSA-heme-Fe(II)-NO (i.e., $K=(1.2 \pm 0.2) \times 10^{-3} \mathrm{M}$ and $(6.2 \pm 0.7) \times 10^{-5} \mathrm{M}$, respectively) were determined. The increase of $k_{\text {off }}$ values reflects the stabilization of the basic form of HSA-heme-Fe by ligands (e.g., abacavir and warfarin) that bind to Sudlow's site I. This event parallels the stabilization of the six-coordinate derivative of the HSAheme-Fe(II)-NO atom. Present data highlight the allosteric modulation of HSA-heme-Fe(II) reactivity by heterotropic effectors.
\end{abstract}

(C) 2008 Elsevier Inc. All rights reserved.

Keywords: Ferrous nitrosylated human serum heme-albumin; Drug-dependent denitrosylation kinetics; Abacavir; Warfarin; Allostery

Human serum albumin (HSA), the most prominent protein in plasma, provides a depot and carrier for many compounds, affects pharmacokinetics of many drugs, holds some ligands in a strained orientation providing their metabolic modification, renders harmless potential toxins transporting them to disposal sites, accounts for most of the antioxidant capacity of human serum, and displays (pseudo-)enzymatic properties [1-15].

Abbreviations: $\mathrm{Hb}$, hemoglobin; HPX, hemopexin; HSA, human serum albumin; Lb, leghemoglobin; Mb, myoglobin; Ngb, neuroglobin; sGC, soluble guanylyl cyclase; trHbO, truncated $\mathrm{Hb} \mathrm{O}$; IHP, inositol hexakisphosphate; 1-MeIm, 1-methylimidazole.

* Corresponding author. Address: Department of Biology and Interdepartmental Laboratory for Electron Microscopy, University 'Roma Tre', Viale Guglielmo Marconi 446, I-00146 Roma, Italy. Fax: +39 065517 6321.

E-mail address: ascenzi@uniroma3.it (P. Ascenzi).
HSA displays a three-domain modular structure probably arising from duplication(s) and divergent evolution of an ancestral gene followed by a fusion event(s). Terminal regions of sequential domains contribute to the formation of flexible interdomain helices linking domain I to II, and II to III, respectively. Each domain consists of two separate sub-domains (named A and B) connected by a random coil $[2,3,5,11,13,16,17]$.

HSA provides a variety of inter-domain and intradomain ligand binding sites. Heme binds with $K_{\mathrm{d}}=1.0 \times 10^{-7} \mathrm{M}$ to a site located in subdomain IB, with the tetrapyrrole ring arranged in a D-shaped cavity limited by Tyr138 and Tyr161 that provide $\pi-\pi$ stacking interaction with the porphyrin and supply a donor oxygen (from Tyr161) coordinating the heme iron. Heme propionates point towards the interface between domains I and III and are stabilized by salt bridges with His146 and Lys190 
$[18,19]$. Bulky heterocyclic molecules bind preferentially to Sudlow's site I, whereas Sudlow's site II is preferred by aromatic carboxylates with an extended conformation $[1-15,20]$.

The heme pocket and Sudlow's site I are spectroscopically and functionally coupled, indeed Sudlow's site I ligands affect allosterically heme binding and vice versa. Heme binding to HSA inhibits ligand association to Sudlow's site I by stabilizing the basic (B) state of HSA, whereas ligand association to Sudlow's site I impairs human serum heme-albumin (HSA-heme) formation by stabilizing the neutral $(\mathrm{N})$ state of HSA [9-13,21-23]. Interestingly, HSA-heme binds $\mathrm{NO}$ and $\mathrm{CO}$ and exhibits catalase and peroxidase activity [11,20,24-30]. Furthermore, HSA-heme mutants have been proposed as $\mathrm{O}_{2}$-carriers [31,32]. Remarkably, abacavir modulates allosterically kinetics of peroxynitrite-mediated oxidation of human ferrous nitrosylated HSA-heme (HSA-heme-Fe(II)-NO) [33].

Here, the effect of abacavir (an anti-retroviral drug) and warfarin (an anticoagulant medication) on denitrosylation kinetics of HSA-heme-Fe(II)-NO is reported. Abacavir and warfarin accelerate NO dissociation from HSAheme-Fe(II)-NO, highlighting the allosteric modulation of HSA-heme-Fe(II) reactivity by heterotropic effectors which appears to be linked to the redox state of the HSA-heme-Fe atom.

\section{Materials and methods}

HSA ( $\geqslant 96 \%$, essentially fatty acid free), hemin (protoporphyrin IX$\mathrm{Fe}(\mathrm{III})$ ) chloride, and warfarin were obtained from Sigma-Aldrich (St. Louis, MO, USA). Abacavir was obtained from Glaxo Wellcome (London, UK). NO (from Aldrich Chemical Co., Milwaukee, WI, USA) was purified by flowing it through an $\mathrm{NaOH}$ column in order to remove acidic nitrogen oxides. CO was purchased from Linde AG (Höllriegelskreuth, Germany).

HSA-heme-Fe(II) $\left(7.6 \times 10^{-6} \mathrm{M}\right)$ was prepared by adding a 1.2-molar excess of HSA to the heme-Fe(II) solution $\left(1.0 \times 10^{-1} \mathrm{M}\right.$ sodium phosphate buffer, pH 7.0) at $10.0^{\circ} \mathrm{C}$. HSA-heme-Fe(II)-NO $\left(3.8 \times 10^{-6} \mathrm{M}\right)$ was obtained, under anaerobic conditions, by blowing purified NO over the ferrous heme-protein solution $\left(1.0 \times 10^{-1} \mathrm{M}\right.$ sodium phosphate buffer, $\mathrm{pH} 7.0$ ) at $10.0^{\circ} \mathrm{C}$. Then, the excess of $\mathrm{NO}$ was pumped off gently before recording kinetics $[20,25,27,29]$.

The warfarin stock solution $\left(2.0 \times 10^{-2} \mathrm{M}\right)$ was prepared by dissolving the drug in water at $\mathrm{pH} 10.0$, then adjusting $\mathrm{pH}$ to 7.0 with $\mathrm{HCl}$ [34]. The abacavir stock solution $\left(1.0 \times 10^{-2} \mathrm{M}\right)$ was prepared by dissolving the drug in methanol [35]. Drug stock solutions were then mixed with the HSA-heme-Fe(II)-NO (final concentration, $3.8 \times 10^{-6} \mathrm{M}$ ) solution to obtain the desired final abacavir and warfarin concentration, ranging between $1.0 \times 10^{-5} \mathrm{M}$ and $5.0 \times 10^{-3} \mathrm{M}$.

The CO solution was prepared by keeping in a closed vessel the $1.0 \times 10^{-1} \mathrm{M}$ phosphate buffer solution $(\mathrm{pH} 7.0)$ under $\mathrm{CO}$ at $P=760.0 \mathrm{~mm} \mathrm{Hg}$ anaerobically $\left(T=20.0^{\circ} \mathrm{C}\right)$.

Values of the first-order rate constant for NO dissociation from HSAheme-Fe(II)-NO (i.e., for NO replacement by $\mathrm{CO} ; k_{\text {off }}$ ) were obtained by mixing the HSA-heme-Fe(II)-NO (final concentration, $3.8 \times 10^{-6} \mathrm{M}$ ) solution with the $\mathrm{CO}$ (final concentration, $1.0 \times 10^{-4} \mathrm{M}$ to $5.0 \times 10^{-4} \mathrm{M}$ ) dithionite (final concentration, $1.0 \times 10^{-2} \mathrm{M}$ ) solution under anaerobic conditions, at $\mathrm{pH} 7.0\left(1.0 \times 10^{-1} \mathrm{M}\right.$ phosphate buffer $)$ and $T=20.0^{\circ} \mathrm{C}$ [36], in the absence and presence of abacavir and warfarin (final concentration, $1.0 \times 10^{-5} \mathrm{M}$ to $5.0 \times 10^{-3} \mathrm{M}$ ). Kinetics was monitored between

\author{
$k_{\text {off }}$ \\ HSA-heme-Fe(II)-NO + CO $\rightarrow$ HSA-heme-Fe(II)-CO + NO
}

Scheme 1.

$360 \mathrm{~nm}$ and $460 \mathrm{~nm}$ (wavelength interval $=5 \mathrm{~nm}$ ). Spectra were collected every $30 \mathrm{~s}$.

The time course for HSA-heme-Fe(II)-NO denitrosylation was fitted to a single exponential process according to the minimum reaction mechanism represented by Scheme 1 [36].

Values of $k_{\text {off }}$ were determined from data analysis according to Eq. (1) [37]:

$[\text { HSA-heme-Fe(II)-NO }]_{\mathrm{t}}=[\text { HSA-heme-Fe(II)-NO }]_{\mathrm{i}} \times \mathrm{e}^{-k_{\text {off }} \times t}$

Values of the dissociation equilibrium constant for drug binding to HSA-heme-Fe(II)-NO (i.e., $K$ ) were obtained from the dependence of $k_{\text {off }}$ on the abacavir and warfarin concentration (i.e., [drug]). Values of $K$ were determined from data analysis, according to Eq. (2) [37]:

$k_{\text {obs }}=k_{\text {off }}{ }^{*} \times[\mathrm{drug}] /(K+[\mathrm{drug}])+k_{\mathrm{off}}{ }^{+} \times K /(K+[\mathrm{drug}])$

where $k_{\text {off }}{ }^{*}$ is the $k_{\text {obs }}$ value obtained in the presence of saturating amounts of abacavir or warfarin (i.e., under conditions where [drug] $>>K$ ), and $k_{\text {off }}{ }^{+}$is the $k_{\text {obs }}$ value obtained in the absence of drugs (i.e., under conditions where $[\mathrm{drug}]=0$ ).

\section{Results and discussion}

Under all the experimental conditions, the time course for NO dissociation from HSA-heme-Fe(II)-NO conforms to a single-exponential decay for more than $90 \%$ of its course, in the absence and presence of abacavir and warfarin (Fig. 1). Values of the first-order rate constant for NO dissociation from HSA-heme-Fe(II)-NO (i.e., $k_{\text {off }}$ ) are wavelength- and [CO]-independent in the presence of dithionite excess (data not shown).

Values of $k_{\text {off }}$ for HSA-heme-Fe(II)-NO denitrosylation increase from $(1.3 \pm 2) \times 10^{-4} \mathrm{~s}^{-1}$, in the absence of drugs (i.e., $k_{\text {off }}^{+}$in Eq. (2)), to $(8.6 \pm 0.9) \times 10^{-4} \mathrm{~s}^{-1}$, in the presence of saturating amounts of abacavir and warfarin (i.e., $k_{\text {off }}{ }^{*}$ in Eq. (2)) (Fig. 1 and Table 1). This finding reflects the stabilization of the B state of HSA-heme-Fe by ligands (e.g., abacavir and warfarin) that bind to Sudlow's site I [9-13,21-23]. This event is accompanied by the stabilization of the six-coordinate derivative of the HSA-heme-Fe(II)-NO species, which is instead predominantly five-coordinated in the $\mathrm{N}$ state (i.e., in the absence of ligands of Sudlow's site I) $[11,20,27,29]$.

The 6.6-fold increase of the $k_{\text {off }}$ value for NO dissociation from HSA-heme-Fe(II)-NO upon stabilization of the six-coordinated B state by abacavir and warfarin (present study) reflects a behavior similar to that reported for the heme-Fe(II)-NO model compound, where the $k_{\text {off }}$ value for NO dissociation increases by 1400 -folds following the trans binding of 1-methyl-imidazole (1-MeIm) [25] (Table 1). However, the binding in trans of a sixth axial ligand to several ferrous nitrosylated hemoproteins is instead generally accompanied by a decrease of the NO dissociation rate constant. Thus, $k_{\text {off }}$ values for NO dissociation from five-coordinate ferrous nitrosylated hemopro- 

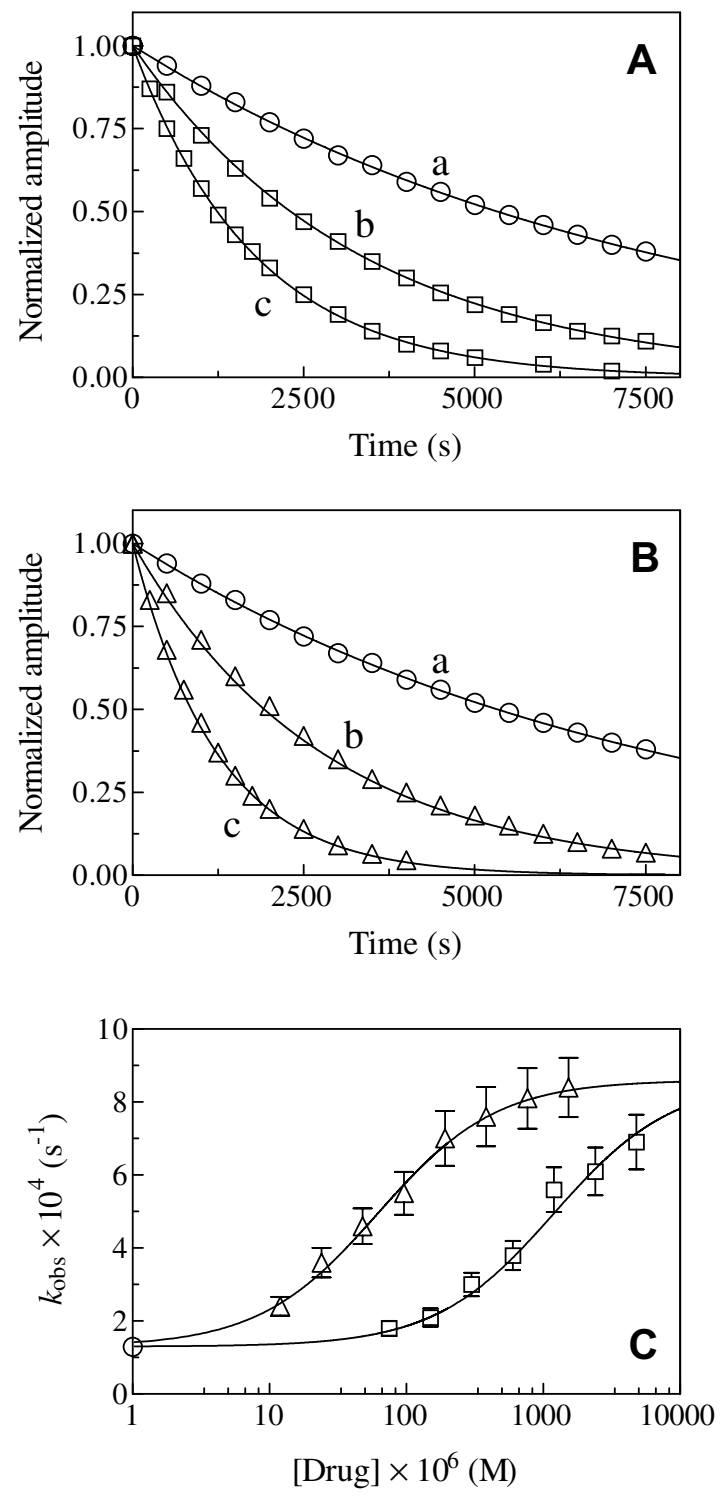

Fig. 1. Kinetics of NO dissociation from HSA-heme-Fe(II)-NO at $\mathrm{pH} 7.0$ and $20.0^{\circ} \mathrm{C}$, in the absence and presence of abacavir and warfarin. (A) Normalized averaged time courses for NO dissociation from HSA-heme$\mathrm{Fe}(\mathrm{II})-\mathrm{NO}$ in the absence (circle) and presence (squares) of abacavir. The time course analysis according to Eq. (1) allowed to determine the following values of $k_{\text {off }}=1.3 \times 10^{-4} \mathrm{~s}^{-1}$ (trace a), $3.0 \times 10^{-4} \mathrm{~s}^{-1}$ (trace b), and $5.6 \times 10^{-4} \mathrm{~s}^{-1}$ (trace c). Values of $k_{\text {obs }}$ were obtained at [abacavir] $=0 \mathrm{M}$ (trace a), $3.0 \times 10^{-4} \mathrm{M}$ (trace b), and $1.2 \times 10^{-3} \mathrm{M}$ (trace c). (B) Normalized averaged time courses for NO dissociation from HSA-heme-Fe(II)-NO in the absence (circle) and presence (triangles) of warfarin. The time course analysis according to Eq. (1) allowed to determine the following values of $k_{\text {off }}=1.3 \times 10^{-4} \mathrm{~s}^{-1}$ (trace a), $3.6 \times 10^{-4} \mathrm{~s}^{-1}$ (trace b), and $8.1 \times 10^{-4} \mathrm{~s}^{-1}$ (trace c). Values of $k_{\text {obs }}$ were obtained at [warfarin] $=0 \mathrm{M}$ (trace a), $2.4 \times 10^{-5} \mathrm{M}$, (trace b), and $7.7 \times 10^{-4} \mathrm{M}$ (trace c). (C) Dependence of $k_{\text {obs }}$ on the abacavir (squares) and warfarin (triangles) concentration (i.e., [drug]). The circle indicates the value of $k_{\text {off }}$ in the absence of drugs. The analysis of data according to Eq. (2) allowed to determine the following parameters: abacavir $-k_{\mathrm{off}}{ }^{*}=(8.6 \pm 0.9) \times 10^{-4} \mathrm{~s}^{-1}, k_{\mathrm{off}}{ }^{+}=(1.3 \pm 0.2) \times$ $10^{-4} \mathrm{~s}^{-1}$, and $K=(1.2 \pm 0.2) \times 10^{-3} \mathrm{M}$; and warfarin $-k_{\mathrm{off}}{ }^{*}=(8.6 \pm 0.9)$ $\times 10^{-4} \mathrm{~s}^{-1}, k_{\mathrm{off}}^{+}=(1.3 \pm 0.2) \times 10^{-4} \mathrm{~s}^{-1}$, and $K=(6.2 \pm 0.7) \times 10^{-5} \mathrm{M}$. Spectra were collected every $30 \mathrm{~s}$. The $\mathrm{CO}$ concentration ranged between $1.0 \times 10^{-4} \mathrm{M}$ and $5.0 \times 10^{-4} \mathrm{M}$. The dithionite concentration was $1.0 \times 10^{-2} \mathrm{M}$. The HSA-heme-Fe(II)-NO concentration was $3.8 \times 10^{-6} \mathrm{M}$. teins are higher than those of six-coordinate species (Table 1) (see $[25,38-43]$ and present study).

The trans base effect, that appears to modulate $k_{\text {off }}$ for denitrosylation of the heme-Fe(II)-NO model compound and HSA-heme-Fe(II)-NO (Table 1), can be counterbalanced and eventually overwhelmed by multiple protein structure-dependent 'cage effects' occurring in most of the six-coordinate ferrous nitrosylated heme-proteins. In spite of the fact that the heme in HSA-heme-Fe is highly solvent accessible $[18,19]$, as also reported for the heme-Fe model compound [25], there is a significant likelihood that, following dissociation, NO undergoes the geminate recombination with the heme-Fe(II) atom before it escapes to the surrounding solvent [25]. This phenomenon, which seems to be more evident in five-coordinated heme-Fe(II)-NO species than in six-coordinated derivatives [44], might contribute significantly to the slower NO dissociation rate constant of the five-coordinated HSA-heme-Fe(II)-NO (in the absence of drugs) with respect to the six-coordinated form (in the presence of drugs) (Table 1).

Furthermore, values of $k_{\text {off }}$ for NO dissociation from ferrous nitrosylated heme-proteins (Table 1) reflect structurally different stabilization mode(s) of the heme-Fe(II)bound NO by amino-acid residue(s) located in the heme distal pocket. In fact, a hydrogen bonding network involving distal Tyr and Trp residues stabilizes the heme-bound ligand in Mycobacterium tuberculosis truncated hemoglobin $\mathrm{O}(\operatorname{trHbO})[45,46]$. Furthermore, Tyr145 stabilizes the heme-bound NO in soluble guanylyl cyclase (sGC) by hydrogen bonding [47]. In contrast, the stabilization of the heme-bound ligand is achieved by hydrogen bonding to the heme distal His residue in human hemoglobin $(\mathrm{Hb})$, horse heart myoglobin $(\mathrm{Mb})$, human neuroglobin $(\mathrm{Ngb})$, and soybean leghemoglobin (Lb), and possibly in rabbit hemopexin-heme (HPX-heme) [38,39,48-53]. Lastly, Arg145 may stabilize the HSA-heme-Fe(II)-NO complex by hydrogen bonding (unpublished results).

In contrast, values of the first-order rate constant for NO dissociation from ferric nitrosylated heme-model compounds and heme-proteins are higher than those of $k_{\text {off }}$ by at least two orders of magnitude, spanning from $1.2 \times 10^{-1} \mathrm{~s}^{-1}$ to $2.6 \times 10^{1} \mathrm{~s}^{-1}$ (see [33]), this reflects the low affinity of NO for heme-Fe(III) systems [37]. Furthermore, values of the first-order rate constant for NO dissociation from HSA-heme-Fe(III)-NO are unaffected by abacavir [33], suggesting an interplay between the allosteric modulation of HSA-heme-Fe reactivity and the redox state of the heme-Fe atom.

The analysis of the dependence of $k_{\text {off }}$ on the drug concentration (Fig. 1) according to Eq. (2) allowed to determine values of the dissociation equilibrium constant for abacavir and warfarin binding to HSA-heme-Fe(II)-NO (i.e., $K=1.2 \times 10^{-3} \mathrm{M}$ and $6.2 \times 10^{-5} \mathrm{M}$, respectively) (Fig. 1). Values of $K$ for abacavir and warfarin binding to HSA-heme-Fe(II)-NO are about 3-fold lower than those reported for drug binding to HSA-heme-Fe(III) $\left(K=4.5 \times 10^{-4} \mathrm{M} \quad\right.$ and $2.1 \times 10^{-5} \mathrm{M}, \quad$ respectively $)$ 
Table 1

Values of $k_{\text {off }}$ for denitrosylation of some heme-Fe(II)-NO systems and heme-Fe(II)-NO coordination state

\begin{tabular}{|c|c|c|c|}
\hline Heme-Fe(II)-NO system & Effector & $k_{\mathrm{off}}\left(\mathrm{s}^{-1}\right)^{\mathrm{a}}$ & Coordination \\
\hline \multirow[t]{2}{*}{$\mathrm{Heme}-\mathrm{Fe}^{\mathrm{b}}$} & - & $2.1 \times 10^{-5}$ & $5 \mathrm{c}$ \\
\hline & 1-MeIm & $2.9 \times 10^{-2}$ & $6 c$ \\
\hline \multirow[t]{2}{*}{ HSA-heme- $\mathrm{Fe}^{\mathrm{c}}$} & - & $1.3 \times 10^{-4}$ & $5 \mathrm{c}$ \\
\hline & Abacavir, warfarin & $8.6 \times 10^{-4}$ & $6 c$ \\
\hline Rabbit HPX-heme-Fe ${ }^{d}$ & - & $9.1 \times 10^{-4}$ & $6 c$ \\
\hline Bovine sGC ${ }^{\mathrm{e}}$ & - & $8.2 \times 10^{-4}$ & $5 \mathrm{c}$ \\
\hline Mycobacterium leprae $\operatorname{trHbO}^{\mathrm{f}}$ & - & $1.3 \times 10^{-4}$ & $6 c$ \\
\hline Soybean $\mathrm{Lb}^{\mathrm{g}}$ & - & $2.0 \times 10^{-5}$ & $6 c$ \\
\hline Horse heart $\mathrm{Mb}^{\mathrm{h}}$ & - & $1.0 \times 10^{-4}$ & $6 c$ \\
\hline Human $\mathrm{Ngb}^{\mathrm{i}}$ & - & $2.0 \times 10^{-4}$ & $6 c$ \\
\hline Human $\mathrm{Hb}, \mathrm{R}$-state, $\alpha$-chains ${ }^{\mathrm{j}}$ & - & $1.6 \times 10^{-4}$ & $6 c$ \\
\hline Human $\mathrm{Hb}, \mathrm{R}$-state, $\beta$-chains ${ }^{\mathrm{j}}$ & - & $8.0 \times 10^{-5}$ & $6 c$ \\
\hline Human $\mathrm{Hb}, \mathrm{T}$-state, $\alpha$-chains ${ }^{\mathrm{j}}$ & IHP & $4.4 \times 10^{-3}$ & $5 \mathrm{c}$ \\
\hline Human $\mathrm{Hb}$, T-state, $\beta$-chains ${ }^{\mathrm{j}}$ & IHP & $9.4 \times 10^{-5}$ & $6 c$ \\
\hline
\end{tabular}

${ }^{a}$ For details, see Scheme 1.

${ }^{\mathrm{b}} \mathrm{pH} 7.4$ and $T=20.0^{\circ} \mathrm{C}$. Six-coordinate heme-Fe(II)-NO was obtained by adding saturating amounts of 1-MeIm. From [25].

c $\mathrm{pH} 7.0$ and $T=20.0^{\circ} \mathrm{C}$. Six-coordinate HSA-heme-Fe(II)-NO was obtained by adding saturating amounts of abacavir and warfarin. Present study.

${ }^{\mathrm{d}} \mathrm{pH} 7.0$ and $T=10.0^{\circ} \mathrm{C}$. From [42].

${ }^{\mathrm{e}} \mathrm{pH} 7.4$ and $T=20.0^{\circ} \mathrm{C}$. From [25].

${ }^{\mathrm{f}} \mathrm{pH} 7.0$ and $T=20.0^{\circ} \mathrm{C}$. From [43].

${ }^{\mathrm{g}} \mathrm{pH} 7.0$ and $T=20.0^{\circ} \mathrm{C}$. From $[38,39]$.

${ }^{\mathrm{h}} \mathrm{pH} 7.4$ and $T=20.0^{\circ} \mathrm{C}$. From [25].

${ }^{\mathrm{i}} \mathrm{pH} 7.5$ and $T=25.0^{\circ} \mathrm{C}$. From [40].

${ }^{\mathrm{j}} \mathrm{pH} 7.2$ and room temperature. The T-state of human $\mathrm{Hb}$ (II)-NO was obtained by adding saturating amounts of IHP. From [41].

$[10,20]$. In turn, values of $K$ for abacavir and warfarin binding to HSA-heme-Fe(II)-NO (present study) and HSAheme-Fe(III) $[10,20]$ are lower by about 30 - and 10 -folds, respectively, than those reported for drug binding to heme-free HSA $\left(K=4.3 \times 10^{-5} \mathrm{M}\right.$ and $3.0 \times 10^{-6} \mathrm{M}$, respectively) [10,54]. These findings confirm that heme inhibits allosterically abacavir and warfarin binding to HSA $[10,20,54]$ and highlight for the first time the role of the redox state of the HSA-heme-Fe atom on modulating drug association.

As a whole, present data indicate that HSA could be taken as the prototype of monomeric allosteric proteins [11]. Although HSA is formed by a single polypeptide chain, its three-domain modular structure, the presence of interdomain contacts, the flexibility of interdomain connections, and the presence of ligand binding sites in the contact regions endow HSA with allosteric properties, heterotropic interactions modulating the conformational transition between at least two different states [11,13]. Remarkably, HSA-heme represents a unique case within heme-proteins since allosteric effectors modulate both the affinity of the heme-Fe for the protein matrix and the heme reactivity.

\section{Acknowledgments}

This work was partially supported by grants from the Ministry for University and Research of Italy (Department of Biology, University 'Roma Tre', Roma, Italy, 'CLAR $2007^{\prime}$ ) and from the Ministry of Health of Italy (National
Institute for Infectious Diseases I.R.C.C.S. 'Lazzaro Spallanzani', Roma, Italy, 'Ricerca corrente 2007') to P.A.

\section{References}

[1] G. Sudlow, D.J. Birkett, D.N. Wade, The characterization of two specific drug binding sites on human serum albumin, Mol. Pharmacol. 11 (1975) 824-832.

[2] D.C. Carter, J.X. Ho, Structure of serum albumin, Adv. Protein Chem. 45 (1994) 153-203.

[3] T. PetersJr. (Ed.), All about Albumin: Biochemistry, Genetics and Medical Applications, Academic Press, San Diego and London, 1996.

[4] C. Bertucci, E. Domenici, Reversible and covalent binding of drugs to human serum albumin: methodological approaches and physiological relevance, Curr. Med. Chem. 9 (2002) 1463-1481.

[5] S. Curry, Beyond expansion: structural studies on the transport roles of human serum albumin, Vox Sang. 83 (1) (2002) 315-319.

[6] U. Kragh-Hansen, V.T. Chuang, M. Otagiri, Practical aspects of the ligand-binding and enzymatic properties of human serum albumin, Biol. Pharm. Bull. 25 (2002) 695-704.

[7] Y. Sakurai, S.F. Ma, H. Watanabe, N. Yamaotsu, S. Hirono, Y. Kurono, U. Kragh-Hansen, M. Otagiri, Esterase-like activity of serum albumin: characterization of its structural chemistry using p-nitrophenyl esters as substrates, Pharm. Res. 21 (2004) 285292.

[8] A. Sułkowska, B. Bojko, J. Równicka, W. Sułkowski, Competition of drugs to serum albumin in combination therapy, Biopolymers 74 (2004) 256-262.

[9] P. Ascenzi, A. Bocedi, S. Notari, E. Menegatti, M. Fasano, Heme impairs allosterically drug binding to human serum albumin Sudlow's site I, Biochem. Biophys. Res. Commun. 334 (2005) 481-486.

[10] A. Bocedi, S. Notari, E. Menegatti, G. Fanali, M. Fasano, P. Ascenzi, Allosteric modulation of anti-HIV drug and ferric heme binding to human serum albumin, FEBS J. 272 (2005) 6287-6296.

[11] M. Fasano, S. Curry, E. Terreno, M. Galliano, G. Fanali, P. Narciso, S. Notari, P. Ascenzi, The extraordinary ligand binding properties of human serum albumin, IUBMB Life 57 (2005) 787-796. 
[12] J. Ghuman, P.A. Zunszain, I. Petitpas, A.A. Bhattacharya, M. Otagiri, S. Curry, Structural basis of the drug-binding specificity of human serum albumin, J. Mol. Biol. 353 (2005) 38-52.

[13] P. Ascenzi, A. Bocedi, S. Notari, G. Fanali, R. Fesce, M. Fasano, Allosteric modulation of drug binding to human serum albumin, Mini Rev. Med. Chem. 6 (2006) 483-489.

[14] G.A. Ascoli, E. Domenici, C. Bertucci, Drug binding to human serum albumin: abridged review of results obtained with high-performance liquid chromatography and circular dichroism, Chirality 18 (2006) 667-679.

[15] V.T. Chuang, M. Otagiri, Stereoselective binding of human serum albumin, Chirality 18 (2006) 159-166.

[16] X. He, D.C. Carter, Atomic structure and chemistry of human serum albumin, Nature 358 (1992) 209-215.

[17] S. Sugio, A. Kashima, S. Mochizuki, M. Noda, K. Kobayashi, Crystal structure of human serum albumin at $2.5 \AA$ resolution, Protein Eng. 12 (1999) 439-446.

[18] M. Wardell, Z. Wang, J.X. Ho, J. Robert, F. Ruker, J. Ruble, D.C. Carter, The atomic structure of human methemalbumin at $1.9 \AA$, Biochem. Biophys. Res. Commun. 291 (2002) 813-819.

[19] P.A. Zunszain, J. Ghuman, T. Komatsu, E. Tsuchida, S. Curry, Crystal structural analysis of human serum albumin complexed with hemin and fatty acid, BMC Struct. Biol. 3 (2003) 6.

[20] S. Baroni, M. Mattu, A. Vannini, R. Cipollone, S. Aime, P. Ascenzi, M. Fasano, Effect of ibuprofen and warfarin on the allosteric properties of haem-human serum albumin: a spectroscopic study, Eur. J. Biochem. 268 (2001) 6214-6220.

[21] L.H. Janssen, M.T. Van Wilgenburg, J. Wilting, Human serum albumin as an allosteric two-state protein: evidence from effects of calcium and warfarin on proton binding behaviour, Biochim. Biophys. Acta 669 (1981) 244-250.

[22] G. Fanali, R. Fesce, C. Agrati, P. Ascenzi, M. Fasano, Allosteric modulation of myristate and $\mathrm{Mn}(\mathrm{III})$ heme binding to human serum albumin: optical and NMR spectroscopy characterization, FEBS J. 272 (2005) 4672-4683.

[23] G. Fanali, A. Bocedi, P. Ascenzi, M. Fasano, Modulation of heme and myristate binding to human serum albumin by anti-HIV drugs. An optical and NMR spectroscopic study, FEBS J. 274 (2007) 44914502.

[24] M.C. Marden, E.S. Hazard, L. Leclerc, Q.H. Gibson, Flash photolysis of the serum albumin-heme-CO complex, Biochemistry 28 (1989) $4422-4426$.

[25] V.G. Kharitonov, V.S. Sharma, D. Magde, D. Koesling, Kinetics of nitric oxide dissociation from five- and six-coordinate nitrosyl hemes and heme proteins, including soluble guanylate cyclase, Biochemistry 36 (1997) 6814-6818.

[26] T. Komatsu, Y. Matsukawa, E. Tsuchida, Kinetics of $\mathrm{CO}$ and $\mathrm{O}_{2}$ binding to human serum albumin-heme hybrid, Bioconjug. Chem. 11 (2000) 772-776.

[27] M. Mattu, A. Vannini, M. Coletta, M. Fasano, P. Ascenzi, Effect of bezafibrate and clofibrate on the heme-iron geometry of ferrous nitrosylated heme-human serum albumin: an EPR study, J. Inorg. Biochem. 84 (2001) 293-296.

[28] E. Monzani, B. Bonafé, A. Fallarini, C. Redaelli, L. Casella, L. Minchiotti, M. Galliano, Enzymatic properties of hemalbumin, Biochim. Biophys. Acta 1547 (2001) 302-312.

[29] M. Fasano, M. Mattu, M. Coletta, P. Ascenzi, The heme-iron geometry of ferrous nitrosylated heme-serum lipoproteins, hemopexin, and albumin: a comparative EPR study, J. Inorg. Biochem. 91 (2002) 487-490

[30] J.K. Kamal, D.V. Behere, Spectroscopic studies on human serum albumin and methemalbumin: optical, steady-state, and picosecond time-resolved fluorescence studies, and kinetics of substrate oxidation by methemalbumin, J. Biol. Inorg. Chem. 7 (2002) 273-283.

[31] T. Komatsu, N. Ohmichi, A. Nakagawa, P.A. Zunszain, S. Curry, E. Tsuchida, $\mathrm{O}_{2}$ and $\mathrm{CO}$ binding properties of artificial hemoproteins formed by complexing iron protoporphyrin IX with human serum albumin mutants, J. Am. Chem. Soc. 127 (2005) 15933-15942.
[32] T. Komatsu, A. Nakagawa, P.A. Zunszain, S. Curry, E. Tsuchida, Genetic engineering of the heme pocket in human serum albumin: modulation of $\mathrm{O}_{2}$ binding of iron protoporphyrin IX by variation of distal amino acids, J. Am. Chem. Soc. 129 (2007) 11286-11295.

[33] P. Ascenzi, M. Fasano, Abacavir modulates peroxynitrite-mediated oxidation of ferrous nitrosylated human serum heme-albumin, Biochem. Biophys. Res. Commun. 353 (2007) 469-474.

[34] G. Fanali, P. Ascenzi, M. Fasano, Effect of prototypic drugs ibuprofen and warfarin on global chaotropic unfolding of human serum heme-albumin: a fast-field-cycling $1 \mathrm{H}-\mathrm{NMR}$ relaxometric study, Biophys. Chem. 129 (2007) 29-35.

[35] A. Bocedi, S. Notari, P. Narciso, A. Bolli, M. Fasano, P. Ascenzi, Binding of anti-HIV drugs to human serum albumin, IUBMB Life 56 (2004) 609-614.

[36] E.G. Moore, Q.H. Gibson, Cooperativity in the dissociation of nitric oxide from hemoglobin, J. Biol. Chem. 251 (1976) 2788-2794.

[37] E. Antonini, M. Brunori, Hemoglobin and Myoglobin in their Reactions with Ligands, North-Holland Publishing Co., Amsterdam, 1971.

[38] E.H. Harutyunyan, T.N. Safonova, I.P. Kuranova, A.N. Popov, A.V Teplyakov, G.V. Obmolova, B.K. Vainshtein, G.G. Dodson, J.C. Wilson, The binding of carbon monoxide and nitric oxide to leghaemoglobin in comparison with other haemoglobins, J. Mol. Biol. 264 (1996) 152-161.

[39] M.S. Hargrove, J.K. Barry, E.A. Brucker, M.B. Berry, G.N. Phillips Jr., J.S. Olson, R. Arredondo-Peter, J.M. Dean, R.V. Klucas, G. Sarath, Characterization of recombinant soybean leghemoglobin $a$ and apolar distal histidine mutants, J. Mol. Biol. 266 (1997) 1032 1042.

[40] S. Van Doorslaer, S. Dewilde, L. Kiger, S.V. Nistor, E. Goovaerts, M.C. Marden, L. Moens, Nitric oxide binding properties of neuroglobin. A characterization by EPR and flash photolysis, J. Biol. Chem. 278 (2003) 4919-4925.

[41] S. Herold, G. Röck, Mechanistic studies of the oxygen-mediated oxidation of nitrosylhemoglobin, Biochemistry 44 (2005) 6223-6231.

[42] M. Fasano, G. Antonini, P. Ascenzi, $\mathrm{O}_{2}$-mediated oxidation of hemopexin-heme(II)-NO, Biochem. Biophys. Res. Commun. 345 (2006) 704-712.

[43] P. Ascenzi, M. Bolognesi, P. Visca, `NO dissociation represents the rate limiting step for $\mathrm{O}_{2}$-mediated oxidation of ferrous nitrosylated Mycobacterium leprae truncated hemoglobin O, Biochem. Biophys. Res. Commun. 357 (2007) 809-814.

[44] A.F. Duprat, T.G. Traylor, G.-Z. Wu, M. Coletta, V.S. Sharma, K.N. Walda, D. Magde, Myoglobin-NO at low pH: free fourcoordinated heme in the protein pocket, Biochemistry 34 (1995) 2634 2644.

[45] M. Mukai, P.Y. Savard, H. Ouellet, M. Guertin, S.R. Yeh, Unique ligand-protein interactions in a new truncated hemoglobin from Mycobacterium tuberculosis, Biochemistry 41 (2002) 3897-3905.

[46] M. Milani, P.Y. Savard, H. Ouellet, P. Ascenzi, M. Guertin, M. Bolognesi, A TyrCD1/TrpG8 hydrogen bond network and a TyrB10TyrCD1 covalent link shape the heme distal site of Mycobacterium tuberculosis hemoglobin O, Proc. Natl. Acad. Sci. USA 100 (2003) 5766-5771.

[47] E. Martin, V. Berka, E. Bogatenkova, F. Murad, A.L. Tsai, Ligand selectivity of soluble guanylyl cyclase: effect of the hydrogen-bonding tyrosine in the distal heme pocket on binding of oxygen, nitric oxide, and carbon monoxide, J. Biol. Chem. 281 (2006) 27836-27845.

[48] N.L. Chan, J.S. Kavanaugh, P.H. Rogers, A. Arnone, Crystallographic analysis of the interaction of nitric oxide with quaternary-T human haemoglobin, Biochemistry 43 (2004) 118-132.

[49] M. Paoli, B.F. Anderson, H.M. Baker, W.T. Morgan, A. Smith, E.N Baker, Crystal structure of hemopexin reveals a novel high-affinity heme site formed between two $\beta$-propeller domains, Nat. Struct. Biol. 6 (1999) 926-931.

[50] D.M. Copeland, A.H. West, G.B. Richter-Addo, Crystal structures of ferrous horse heart myoglobin complexed with nitric oxide and nitrosoethane, Proteins 53 (2003) 182-192. 
[51] A. Pesce, S. Dewilde, M. Nardini, L. Moens, P. Ascenzi, T. Hankeln, T. Burmester, M. Bolognesi, Human brain neuroglobin structure reveals a distinct mode of controlling oxygen affinity, Structure 11 (2003) 1087-1095.

[52] D. de Sanctis, A. Pesce, M. Nardini, M. Bolognesi, A. Bocedi, P. Ascenzi, Structure-function relationships in the growing hexa-coordinate hemoglobin sub-family, IUBMB Life 56 (2004) 643-651, Erratum in: IUBMB Life 57 (2005) 459-460.
[53] B. Vallone, K. Nienhaus, A. Matthes, M. Brunori, G.U. Nienhaus, The structure of carbonmonoxy neuroglobin reveals a heme-sliding mechanism for-control of ligand affinity, Proc. Natl. Acad. Sci. USA 101 (2004) 17351-17356.

[54] M. Dockal, M. Chang, D.C. Carter, F. Rüker, Five recombinant fragments of human serum albumin-tools for the characterization of the warfarin binding site, Protein Sci. 9 (2000) 1455-1465. 